OPEN ACCESS

Edited by:

Gudrun S. Ulrich-Merzenich, University Hospital Bonn, Germany

Reviewed by: Jen-Tsung Chen, National University of Kaohsiung, Taiwan JiangJie Lu,

Hangzhou Normal University, China Xiaoyu Ding,

Nanjing Normal University, China

*Correspondence: Suiyun Chen chensuiyun@ynu.edu.cn Dake Zhao zhaodk2012@ynu.edu.cn

Specialty section:

This article was submitted to

Ethnopharmacology,

a section of the journal

Frontiers in Pharmacology

Received: 14 September 2020 Accepted: 01 April 2021 Published: 20 April 2021

Citation:

Mou Z, Zhao Y, Ye F, Shi Y, Kennelly EJ, Chen S and Zhao D (2021) Identification, Biological Activities and Biosynthetic Pathway of

Dendrobium Alkaloids.

Front. Pharmacol. 12:605994. doi: 10.3389/fphar.2021.605994

\section{Identification, Biological Activities and Biosynthetic Pathway of Dendrobium Alkaloids}

\author{
Zongmin Mou ${ }^{1}$, Yi Zhao ${ }^{2,3}$, Fei Ye ${ }^{4}$, Yana Shi ${ }^{5,6}$, Edward J. Kennelly ${ }^{2,3}$, Suiyun Chen ${ }^{1 *}$ and \\ Dake Zhao ${ }^{1 *}$
}

${ }^{1}$ Biocontrol Engineering Research Center of Plant Disease and Pest, Biocontrol Engineering Research Center of Crop Disease and Pest, School of Ecology and Environmental Science, Yunnan University, Kunming, China, ${ }^{2}$ Department of Biological Sciences, Lehman College and The Graduate Center, City University of New York, Bronx, NY, United States, ${ }^{3}$ Ph.D. Programs in Biochemistry, Biology, and Chemistry, The Graduate Center, City University of New York, New York, NY, United States, ${ }^{4}$ Kunming Municipal Hospital of Traditional Chinese Medicine, Kunming, China, ${ }^{5}$ College of Agriculture and Biotechnology, Yunnan Agricultural University, Kunming, China, ${ }^{6}$ Institute of Medicinal Plants, Yunnan Academy of Agricultural Sciences, Kunming, China

Dendrobium is a genus of flowering plants belonging to the Orchidaceae family with more than 1,400 species. Many Dendrobium species have been used as medicinal plants in several Asian countries for thousands of years. Alkaloids were reported as the major biological markers due to their complex chemical compositions and various types. In this review, we summarized the structural types of alkaloids, their pharmacological activities, as well as the mechanisms of biological activities. More than sixty alkaloids were isolated and identified from the Dendrobium genus. Moreover, the pharmacological effects of Dendrobium alkaloids as hepatic lipid and gluconeogenesis regulation, as neuroprotection, and as anti-tumor, anti-inflammatory, anti-diabetes, and anti-virus factors were described. Besides, the total chemical synthesis of dendrobine is provided, while the biosynthetic pathway of dendrobine has been proposed based on the functions of associated genes. For applications of these invaluable herbs, more researches on the extraction of biological markers from compounds are needed. Further confirmation of the proposed biosynthetic pathways is anticipated as well.

Keywords: alkaloids, orchidaceae, Dendrobium, anti-inflammatory, antitumor, mechanisms, biosynthetic pathway

\section{INTRODUCTION}

Apart from Asteraceae, the orchid family is the second-largest flowering family, which has 28,000 species distributed in about 736 genera (Chase et al., 2015), among which Dendrobium is one of the largest genera. It contains more than 1,500 species (www.theplantlist.org), most of which are epiphytic or lithophytic, and it is widespread in South, East, and Southeast Asia, like China, Japan, Philippines, Vietnam, India, and Indonesia. Some species are also found in New Guinea, Australia, and the islands of the Pacific (Zhu et al., 2009). The plants of Dendrobium species have been used as traditional or folk medicine in many Asian countries for thousands of years. For instance, there are 96 Dendrobium species in China, and about 30 species, known as shí hú (石斛) or shí hú lán (石斛 兰), have been widely used as ethnic medicine for tonifying the stomach, nourishing Yin (to enhance the production of body fluids, such as blood, saliva, tears, etc.), and clearing heat and toxic matter (Yang et al., 2006; Flora of China, 2020). The earliest written record of the medicinal usage of Dendrobium was found in the ancient text "Shen Nong's Herbal Classic" 2000 years ago, in which it was considered to be a "superior grade" herbal medicine. Hundreds of years later, Dendrobium was 
TABLE 1 | The ethnomedicine use of Dendrobium in some countries.

\begin{tabular}{|c|c|c|c|c|}
\hline Country & Dendrobium species & Local name & Ethnomedicine use & References \\
\hline \multirow{7}{*}{ China } & Dendrobium chrysotoxum Lindl. & $\begin{array}{l}\text { shí hú lán } \\
\text { (石斛兰) }\end{array}$ & Used for clearing heat and toxic matter, and enhancing immunity & Lin et al. (2018) \\
\hline & Dendrobium fimbriatum Hook. & $\begin{array}{l}\text { huáng cǎo } \\
\text { (黄草) }\end{array}$ & & Yang et al. (2006) \\
\hline & Dendrobium officinale Kimura et Migo & xiān căo (仙草) & & Yuan et al. (2018) \\
\hline & Dendrobium aphyllum (Roxb.) C.E.C.Fisch & & & Wang et al. (2020) \\
\hline & Dendrobium findlayanum C. S. P. Parish et & & & \\
\hline & Rchb. f. & & & \\
\hline & Dendrobium loddigesii Rolfe & & & \\
\hline Japan & Dendrobium moniliforme (L.) Sw. & Fu-ran & Gives long life to men & $\begin{array}{l}\text { Cakova et al. } \\
(2020)\end{array}$ \\
\hline Indian & Dendrobium macraei Lindl. (jeevanti) & $\begin{array}{l}\text { Charaka } \\
\text { samhita }\end{array}$ & $\begin{array}{l}\text { Used as an astringent to the bowels, as anaphrodisiac, and in asthma } \\
\text { and bronchitis }\end{array}$ & Lam et al. (2015) \\
\hline
\end{tabular}

documented in detail in "Compendium of Materia Medica" in Ming Dynasty (1590 AD). Nowadays, Dendrobium nobile Lindl., Dendrobium chrysotoxum Lindl., Dendrobium fimbriatum Hook., Dendrobium officinale Kimura et Migo, and Dendrobium huoshanense Z. Z. Tang et S. J. Cheng are included in Chinese Pharmacopoeia (2020 edition). Among these five species, Dendrobium nobile Lindl. is one of the 50 fundamental herbs used in traditional Chinese medicine (TCM). Generally, the fibrous stems of Dendrobium are employed as the officinal parts in ethnopharmacology, persevered by dry processing (Chinese Pharmacopoeia Commission, 2020). These stems are usually used either alone or mixed with other tonic Chinese herbs, like xī yáng shēn (American Ginseng) and gǒu qǐ zǐ (Barbary Wolferry Fruit) (Lin et al., 2018). Aside from China, Dendrobium species have also been used as ethnomedicines in Japan, Indian, and Thailand (Table 1). Given their high medicinal value and wide ethno-applications, the Dendrobium genus was recognized as a prized folk medicine ( $\mathrm{Ng}$ et al., 2012).

Due to the important pharmacological activities and economical value of Dendrobium genus, up to now, many phytochemical and pharmacological researches have been implemented. The active constituents in Dendrobium are polysaccharides, alkaloids, flavonoids, amino acids, bibenzyls, and several trace elements (He et al., 2020). The polysaccharides from Dendrobium exhibit immunomodulatory and hepatoprotective activities; and the alkaloids are antioxidant, anticancer, and neuroprotective, while other compounds display anti-angiogenesis, anticytotoxicity, and anti-mutagenesis effects ( $\mathrm{Ng}$ et al., 2012; $\mathrm{Xu}$ et al., 2013). Alkaloids are the earliest identified category of compounds in Dendrobium (Chen and Chen, 1935). More importantly, Dendrobium alkaloids are the key constituents that responsible for their pharmacological activities, making them potential candidates for new drugs. Therefore, some important bioactive markers such as dendrobine (20) have attracted many scientists to investigate their chemical, pharmaceutical, and biological mechanisms, as well as biogenetic pathways (Li Q. et al., 2017).

Dendrobium alkaloids with complex chemical structures consist of pyrrole, indolizidine, terpenoid alkaloids, organic amine alkaloids, indole, quinazoline, and others ( $\mathrm{Xu}$ et al., 2013). In accordance with other genera of Orchidaceae plants, indolizidine alkaloids and organic amine alkaloids are the major constituents of this genus (Lam et al., 2015). These chemicals are considered as active ingredients for effects like antiinflammatory, cytotoxic, antitumor, cytoprotection, gluconeogenesis regulation, and preventing neuronal apoptosis (Ng et al., 2012). For instance, Dendrobium nobile Lindl. is a famous TCM recorded in Chinese Pharmacopoeia (2020 edition). The alkaloids of Dendrobium nobile Lindl. (DNLA) are considered to have beneficial effects on liver metabolism, hepatic lipid homeostasis, neuronal activity, and resistance effects on tumors, cancers, and virus based on previous studies (Table 2). Dendrobine (20), a sesquiterpene alkaloid, makes up 92.6\% of the DNLA (Xu et al., 2017). Dendrobine (20) is the first identified active alkaloid of Dendrobium nobile Lindl. (Chen and Chen, 1935), and is regarded as the standard agent for qualitative and quantitative evaluation of Dendrobium nobile Lindl. (Li R. et al., 2017).

In this review, we aim to summarize the structural types, pharmacological activities, and the mechanisms of biological activities of Dendrobium alkaloids. Additionally, the proposed biogenetic pathways of dendrobine (20) are also included.

\section{STRUCTURAL IDENTIFICATION OF DENDROBIUM ALKALOIDS}

Alkaloids are representatives of the first category of compounds extracted from Dendrobium (Xu et al., 2013). Dendrobium alkaloids were isolated by the traditional alkaloid extraction method given their basic chemical structure. Dried powders of 
TABLE 2 | Summary of the pharmacological of alkaloids isolated from Dendrobium nobile Lindl.

\begin{tabular}{|c|c|c|c|c|c|}
\hline No & Organ & $\begin{array}{l}\text { Alkaloids } \\
\text { content } \\
\text { of crude } \\
\text { extract }\end{array}$ & $\begin{array}{l}\text { Constituents of } \\
\text { alkaloid extract }\end{array}$ & $\begin{array}{l}\text { Pharmacological } \\
\text { activities }\end{array}$ & References \\
\hline \multirow[t]{6}{*}{1} & Stem & $79.8 \%$ & Dendrobine (20), 92.6\% & Beneficial effects on liver glucose and lipid metabolism gene & Xu et al. (2017) \\
\hline & & & $\begin{array}{l}\text { Dendrobine-N-oxide } \\
(22), 3.3 \%\end{array}$ & expressions & Li et al. (2019) \\
\hline & & & Nobilonine (45), 2.0\% & & \\
\hline & & & Dendroxine (24), 0.9\% & & \\
\hline & & & $\begin{array}{l}\text { 6-Hydroxy-nobilonine } \\
\text { (46), } 0.32 \%\end{array}$ & & \\
\hline & & & $\begin{array}{l}\text { 13-Hydroxy-14- } \\
\text { oxodendrobine (26), } 0.07 \%\end{array}$ & Protective effects on $\mathrm{CCl}_{4}$-induced acute liver injury & \\
\hline 2 & Stem & $79.8 \%$ & Dendrobine (20), 92.6\% & $\begin{array}{l}\text { Protective effects on hepatic lipid homeostasis and acute liver } \\
\text { injury }\end{array}$ & $\begin{array}{l}\text { Huang S. et al. (2019); } \\
\text { Zhou et al. (2020) }\end{array}$ \\
\hline 3 & Stem & Unkown & Mixed fat-soluble alkaloids & Anti-tumor efficacy in human colorectal cancer & He et al. (2017) \\
\hline \multirow[t]{5}{*}{4} & Unkown & $96.1 \%$ & Dendrobine (20), 90.7\% & Protection from OGD/RP-induced neuronal damages & Wang et al. (2010) \\
\hline & & & Dendramine (23), 2.31\% & & \\
\hline & & & 3-Hydroxy-2-oxodendrobine & & \\
\hline & & & (26), $1.29 \%$ & & \\
\hline & & & Nobilonine, (45), 4.47\% & & \\
\hline \multirow[t]{4}{*}{5} & Stem & $96.1 \%$ & Dendrobine (20), 90.7\% & Protection of brain impairment & Li et al. (2011) \\
\hline & & & Nobilonine (45), 4.47\% & & \\
\hline & & & Dendramine (23), 2.31\% & & \\
\hline & & & $\begin{array}{l}\text { 3-Hydroxy-2-oxodendrobine } \\
\text { (26), } 1.29 \%\end{array}$ & & \\
\hline 6 & Unkown & $54.5 \%$ & Dendrobine (20), 30.5\% & $\begin{array}{l}\text { Attenuation of LPS-induced hyperphosphorylation of tau protein } \\
\text { and protection against LPS-induced apoptosis }\end{array}$ & Yang et al. (2014) \\
\hline \multirow[t]{6}{*}{7} & Unkown & $79.8 \%$ & Dendrobine $(20)$ & Prevention of neuronal apoptosis and synaptic loss & Nie et al. (2016) \\
\hline & & & Dendrobine-N-oxide (22) & & \\
\hline & & & Nobilonine (45) & Regulation of a- and B-secretase in hippocampal neurons & Huang J. et al. (2019) \\
\hline & & & Dendroxine (24) & & \\
\hline & & & 6-Hydroxy-nobilonine (46) & & \\
\hline & & & $\begin{array}{l}\text { 13-Hydroxy-14- } \\
\text { oxodendrobine (26) }\end{array}$ & & \\
\hline 8 & Dendrobine & $>98 \%$ & Dendrobine (20), >98\% & Anticancer activity toward non-small cell lung cancer cells & Song et al. (2019) \\
\hline & standard & & & & \\
\hline 9 & $\begin{array}{l}\text { Dendrobine } \\
\text { standard }\end{array}$ & $98 \%$ & Dendrobine (20), 98\% & Anti-influenza a virus & Li et al. (2017) \\
\hline
\end{tabular}

Dendrobium spp. were liquid-liquid extracted with various solvents, such as ethanol, methanol, or chloroform, then fractionated successively with water, petroleum ether, ethyl acetate, n-butyl alcohol, etc. (Yang et al., 2020). Subsequently, these fractions were purified on different silica gel column chromatography systems with various polarity ranges of solvents (Morita et al., 2000). Moreover, high performance liquid chromatography (HPLC) and ultra-performance liquid chromatography (UPLC) coupled with mass spectrometry were developed to discover new compounds of Dendrobium (Xu et al., 2020). Up to now, more than sixty alkaloids (Figures 1-5, 1-63) have been identified from this genus. The chemical structures include pyrrole, indolizidine, terpenoid, amine, and indole alkaloids. These compounds were mainly isolated from the whole plants, stems, or leaves of Dendrobium nobile Lindl., Dendrobium officinale Kimura et Migo, Dendrobium findlayanum C. S. P. Parish et Rchb. f., Dendrobium chrysanthum Wall. ex Lindl., Dendrobium crepidatum Lindl. ex Paxton, Dendrobium anosmum Lindl., Dendrobium devonianum Paxton, Dendrobium friedericksianum Rchb. f., Dendrobium hildebrandii Rolfe, Dendrobium loddigesii Rolfe, Dendrobium lohohense Tang et F. T. Wang, Dendrobium moniliforme (L.) Sw., Dendrobium pierardii R. Br., Dendrobium primulinum Lindl., and Dendrobium wardianum R. Warner (Inubushi et al., 1964; Lüning et al., 1965; Elander et al., 1969; Ekevag et al., 1973; Begum et al., 2010; Lam et al., 2015; Hu et al., 2016; Hu et al., 2016; Xu et al., 2019).

\section{Pyrrole Alkaloids}

Most pyrrole alkaloids from Orchidaceae were found in Dendrobium, Pleione, and Liparis plants. Till now, only five pyrroles were reported in Dendrobium, and all of them are simple phthalide-pyrrolidine alkaloids (Figure 1). Shihunine (1), a water-soluble phthalide-type alkaloid, was the first pyrrole alkaloid from Dendrobium lohohense Tang et F. T. Wang in 1968 (Inubushi et al., 1964). Shihunidine (2) was also isolated from the same species by Li et al. (1991). Cis-trans isomerizations of dendrochrysines (3 and 4) and dendrochrysanines (5 and 6), the other four pyrrole isomers 
<smiles>CN1CCCC12OC(=O)c1ccccc12</smiles>

1<smiles>[R]N1CCC[C@H]1CC(=O)CC1CCCN1C</smiles>

$3 \mathrm{R}=$ cis-cinnamoyl

$4 \mathrm{R}=$ trans-cinnamoyl<smiles>CC(=O)C[C@]1(C)CCCN1C(=O)/C=C/c1ccccc1</smiles>

6<smiles>CN1CCCC12NC(=O)c1ccccc12</smiles>

2<smiles>CC(=O)C[C@]1(C)CCCN1C(=O)/C=C/c1ccccc1</smiles>

5<smiles>CC(=O)C[C@@H]1CCCN1C</smiles>

7

FIGURE 1 | Structures of pyrrole alkaloids reported in Dendrobium.

alkaloids, were isolated from Dendrobium chrysanthum Wall. ex Lindl. (Ekevag et al., 1973; Yang et al., 2005), while hygrine (7) was produced in Dendrobium primulinum Lindl. (Lüning et al., 1965).

\section{Indolizidine Alkaloids}

Indolizidine alkaloids are important constituents of Dendrobium (Xu et al., 2019). Twelve indolizidine alkaloids were observed in Dendrobium, most of which were from Dendrobium crepidatum Lindl. et Paxton (Figure 2, 8-19). Dendroprimine (8) is a simple indolizidine alkaloid reported in Dendrobium primulinum Lindl. (Lüning et al., 1965). Other indolizidine alkaloids such as crepidine (9), crepidamine (10), isocrepidamine (11), and isodendrocrepine (12) were found in Dendrobium crepidatum Lindl. et Paxton (Elander et al., 1973; Hu et al., 2020). The other three alkaloids of this type $( \pm)$-homocrepidine A [( \pm )-13] $( \pm)$-dendrocrepidamine A $[( \pm)-14]$, and homocrepidine B (15) were first identified from the same Dendrobium species by $\mathrm{Hu}$ et al. $(2016 ; 2020)$. Then the absolute configurations of the new pairs enantiomeric octahydroindolizine compounds $( \pm)$-homocrepodine A $[( \pm)-13]$ and $( \pm)$ - dendrocrepidamine A $[( \pm)-14]$, were verified by single-crystal X-ray diffraction ( $\mathrm{Hu}$ et al., 2016; Hu et al., 2020). Recently, four new indolizidine alkaloids, crepidatumines A to D (16-19), were purified from Dendrobium crepidatum Lindl. et Paxton by Xu et al. (2019; 2020).

\section{Terpenoid Alkaloids}

Terpenoid alkaloids are another important secondary metabolites principally isolated from Dendrobium (Xu et al., 2013). The types of alkaloids are various based on their mono-, sesqui-, di-, and triterpenoid skeletons. Dendrobine (20) was the first terpenoidalkaloid elucidated from Dendrobium nobile Lindl. in 1932 (Chen and Chen 1935). Subsequently, a total of 25 dendrobine-type alkaloids were found in Dendrobium nobile Lindl., Dendrobium findlayanum C. S. P. Parish et Rchb. f., Dendrobium wardianum R. Warner, and Dendrobium moniliforme (L.) Sw., most of which are sesquiterpenoid alkaloids (Figure 3, 20-42, 51-52). 
<smiles>CC(=O)[C@@H]1[C@@H]2CC[C@@H]3C[C@H](C)[C@@](O)(c4ccccc4)[C@H](C[C@@]1(C)O)N23</smiles><smiles>CC(=O)C[C@@H]1N2CCC[C@H]2CC(C)[C@]1(O)c1ccccc1</smiles><smiles>C[C@H]1C[C@H](C)N2CCC[C@H]2C1</smiles>

10<smiles>CC1C[C@H]2CCCN2C2CC(C)(O)O[C@]12c1ccccc1</smiles><smiles>CCCN1CC[C@H](C)[C@@](O)(c2ccccc2)[C@H]1CC1(O)C[C@H]2N3CCC[C@H]3CC(C)[C@@]2(c2ccccc2)O1</smiles>

12<smiles>CC(=O)C[C@H]1CC[C@H]2C[C@H](C)[C@](O)(c3ccccc3)[C@@H]21</smiles>

16<smiles>[R]C1(c2ccccc2)C(C)C[C@@H]2CCCN2[C@@H]1CC(=O)C[C@H]1N2CCC[C@@H]2C[C@H](C)[C@]1(O)c1ccccc1</smiles>

(+)-13: $\mathrm{R}=\mathrm{OH}$ (+)-14: R=H<smiles>C[C@H]1C[C@H]2CC[C@H]3CC(=O)C[C@H]([C@H]1c1ccccc1)[C@@H]32</smiles>

17<smiles>[R][C@]1(c2ccccc2)[C@@H](C)C[C@@H]2CCCN2[C@@H]1CC(=O)C[C@H]1N2CCC[C@@H]2C[C@H](C)[C@]1(O)c1ccccc1</smiles>

(-)-13: $\mathrm{R}=\mathrm{OH}$ $(-)-14: R=H$

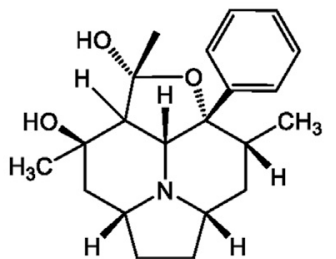

18<smiles>CC(=O)CCCC[C@H]1C[C@H](C)C(O)(c2ccccc2)CN1</smiles>

15

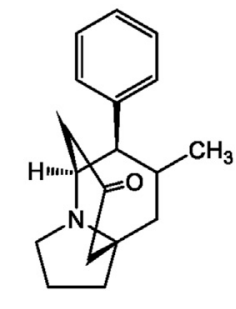

19

FIGURE 2 | Structures of indolizidine alkaloids reported in Dendrobium.

Interestingly, dendrobine-type alkaloids are a class of characteristic picrotoxanes with highly complex structures, which are only distributed in Dendrobium genus (Begum et al., 2010; Meng et al., 2017). All of these dendrobine-type alkaloids contain basic skeletons comprising one picrotoxanetype sesquiterpenoid combined with a five-membered C2-C9lined $\mathrm{N}$-heterocycle and $\mathrm{C} 3$-C5-linked lactonic ring ( $\mathrm{Xu}$ et al., 2013).

Two thirds of terpenoid alkaloids in the genus Dendrobium were isolated from the certain species of Dendrobium nobile Lindl.. Mubironines A-C (27-29) were identified from the whole plant (Morita et al., 2000), and the absolute components of these three compounds were confirmed by single-crystal X-ray diffraction. Dendroterpene A and B $(30-31)$ were found from the stems recently (Wang P. et al., 2019). Other terpenoid alkaloids from Dendrobium nobile Lindl., compounds $20-26$ and $32-41$ have been reported over eighty years (Chen and Chen, 1935; Shhosuke and Yoshimasa, 1964; Inubushi and Nakano, 1965; Okamoto et al., 1966a; Okamoto et al., 1966b; Granelli et al., 1970;
Elander and Leander, 1971; Hedman and Leander, 1972; Okamoto et al., 1972; Glomqvist et al., 1973; Wang et al., 1985; Meng et al., 2017; Wang Q. et al., 2019; Liu et al., 2020; Yang et al., 2020). A total of eleven terpenoid alkaloids were purified from another three Dendrobium species. Dendrofindline B (42) was isolated from Dendrobium findlayanum C. S. P. Parish et Rchb. f. (Liu et al., 2020). Besides, seven new seco-dendrobines, findlayines A-F (43-48), and dendrofindline A (49) were identified from the same species. (Yang et al., 2018; Liu et al., 2020; Yang et al., 2020). In 2007, Liu et al. (2007) reported the isolation and structural identification of moniline (50) from the stems and leaves of Dendrobium moniliforme (L.) Sw.. Dendrowardine (51) and wardianumine A (52) were purified from Dendrobium wardianum R. Warner by Liu and Zhao. (2003) and Zhang et al. 2017, respectively.

\section{Amine Alkaloids}

Amine alkaloids are a class of widely spread natural amines with basic nitrogen but cannot form a ring in the skeleton. Most 


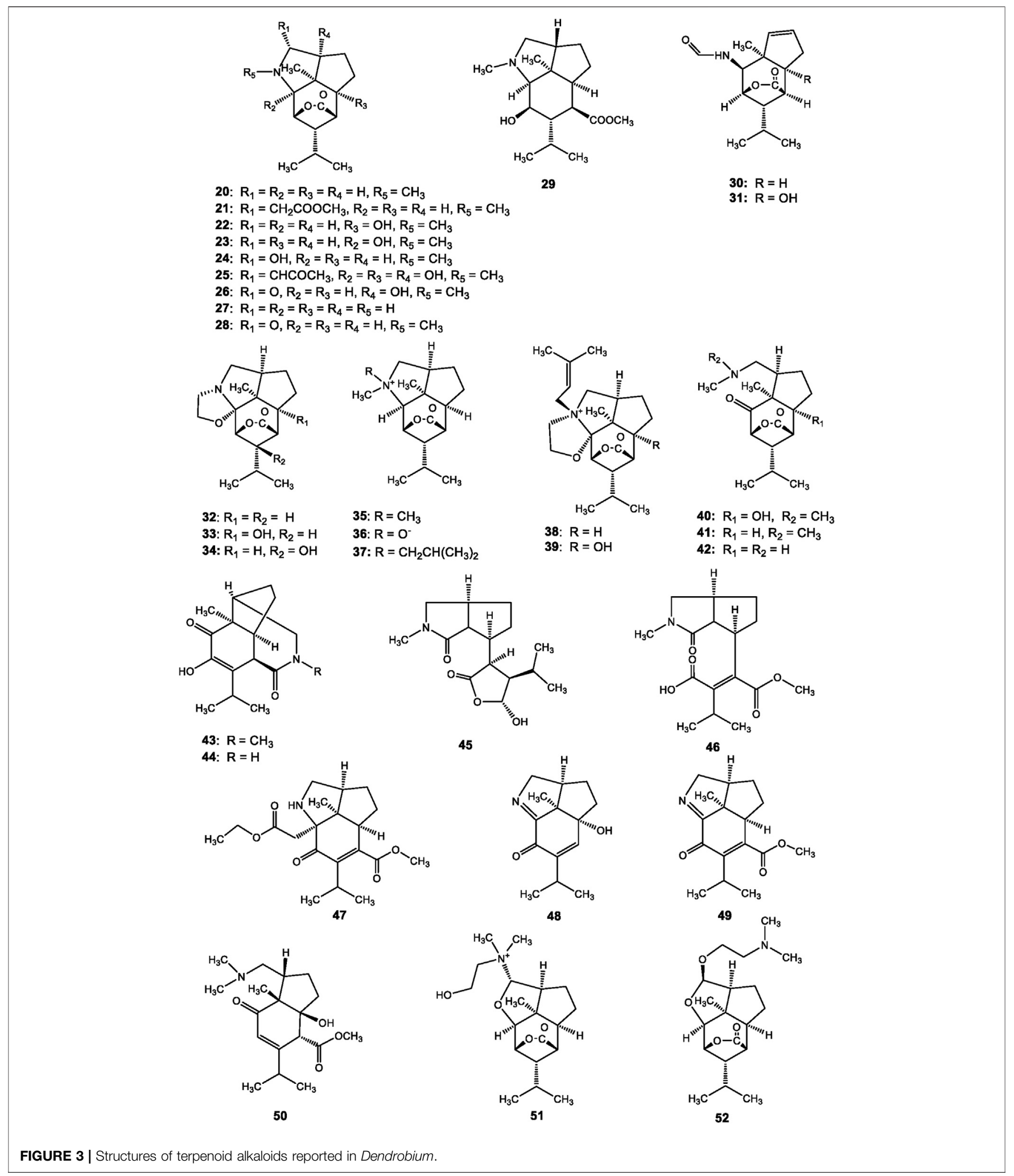

amines in Dendrobium are amides (Figure 4, 53-61). For example, $N$-cis-p-coumaroyltyramine (53) and $\mathrm{N}$-cisferuloyltyramine (54) were identified from the stems of
Dendrobium devonianum Paxton (Zhang et al., 2013). Pierardine (61) was isolated from Dendrobium pierardii R. Br. (Elander et al., 1969). 
<smiles>[R8]c1ccc(/C=C/C(=O)NCCc2ccc(O)cc2)cc1Br</smiles>

53: $\mathrm{R}_{1}=\mathrm{OH} ; \mathrm{R}_{2}=\mathrm{H}$

54: $\mathrm{R}_{1}=\mathrm{OH} ; \mathrm{R}_{2}=\mathrm{OCH}_{3}$

55: $\mathrm{R}_{1}=\mathrm{OH} ; \mathrm{R}_{2}=\mathrm{OH}$

56: $R_{1}=H ; R_{2}=H$<smiles></smiles>

60: $\mathrm{R}=\mathrm{H}$<smiles>[R]c1cc(CCC(=O)NCCc2ccc(O)cc2)ccc1O</smiles>

57: $\mathrm{R}=\mathrm{H}$

58: $\mathrm{R}=\mathrm{OCH}_{3}$<smiles>CN(C)CCC[C@H]1OC(=O)c2ccccc21</smiles>

61

FIGURE 4 | Structures of organic amine alkaloids reported in Dendrobium.

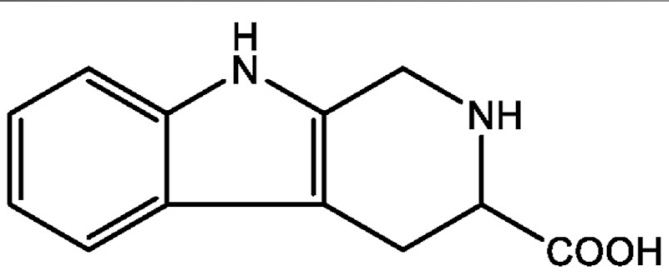

62

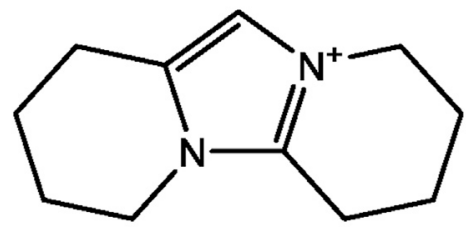

63

FIGURE $\mathbf{5}$ | Structures of indole and other alkaloids reported in Dendrobium.

\section{Indole and Other Types of Alkaloids}

2,3,4,9-tetrahydro-1 H-pyrido [3,4-b] indole-3-carboxylic acid (62) was the only reported indole alkaloid from Dendrobium devonianum Paxton (Zhang et al., 2013) (Figure 5). Moreover, anosmines (63) are another type of alkaloids isolated from two species of Dendrobium, whose structures were confirmed by X-ray crystallography (Hemscheidt and Spenser, 1993).

\section{Metabolic Analysis of Dendrobium}

At present, metabolomics has been widely utilized in the field of medicinal plants, such as bioactive components identification, drug metabolism, toxicology, and investigation on metabolic pathways, etc. (Liang et al., 2009). Alkaloids are regarded as chemical markers in quantitative analysis of Dendrobium. Generally, the metabolic profiling of Dendrobium alkaloid compounds was established by liquid chromatography coupled to single (LC-MS) and tandem (LC-MS/MS) mass spectrometry, in combination with multivariate data analyses, where secondary metabolites can be accurately quantified based on their fingerprint chromatograms. For example, the comparative metabolite analysis of Dendrobium officinale Kimura et Migo and Dendrobium huoshanense Z. Z. Tang et S. J. Cheng showed that the accumulation of alkaloids was species-specific (Song et al., 2020). Ten potential anti-inflammatory alkaloid components were detected from the extraction of Dendrobium aphyllum (Roxb.) C. E. C. Fisch by UPLC-MS (Wang P. et al.,2019), while eight water-soluble metabolites containing rare imidazolium alkaloids and anosmines (4) were identified by the screening of Dendrobium nobile Lindl., Dendrobium officinale Kimura et Migo, and Dendrobium loddigesii Rolfe, using chromatography along with spectroscopic techniques (Chen et al., 2018). Besides, DNLA was reported to improve hepatic lipid homeostasis based on the results of UPLC-MS of 48 kinds of hepatic bile acids in the livers of high fat diet (HFD)-fed mice (Huang S. et al., 2019). Furthermore, the combination of 
metabolomic and transcriptomic technologies revealed the possible pathways in alkaloid biosynthesis of Dendrobium officinale Kimura et Migo (Guo et al., 2013).

\section{PHARMACOLOGICAL ACTIVITIES}

Dendrobium alkaloids are active components with antiinflammatory, antitumor, and anti-viral effects, which can also regulate hepatic lipid and gluconeogenesis, and protect from hyperglycemia. For a better understanding of the bioactivities of Dendrobium alkaloids, previous studies on pharmacological efficacy are summarized.

\section{Anti-inflammatory Activity}

Inflammation induced by endotoxin such as lipopolysaccharide (LPS), is an immune defense response of organisms to tissue injury and microbial agents (Guha and Mackman, 2001). Most anti-inflammatory activities were tested with the LPS-induced RAW264.7 model by evaluating the indices of nitric oxide (NO) production and the expression of inducible NO synthase (Chen et al., 2018). The anti-inflammatory activities of Dendrobium alkaloids have been reported. For example, anosmines (63) that were presented in four Dendrobium species exhibited inhibitory activity against NO production and inflammation in LPSactivated RAW264.7 cells without cytotoxic activity (Chen et al., 2018). Besides (+)-homocrepidine A [(+)-13] isolated from Dendrobium crepidatum Lindl. ex Paxton was evaluated for its anti-inflammatory activity (NO inhibition) with LPSinduced RAW 264.7 macrophages, and the half maximal inhibitory concentration $\left(\mathrm{IC}_{50}\right)$ value was $3.6 \mu \mathrm{M}$. However, the other enantiomeric isomer (-)-homocrepodine A [(-)-13], displayed an $\mathrm{IC}_{50}$ value of $22.8 \mu \mathrm{M}$, which was almost 7 times less active than $[(+)-13]$. Besides, their racemic mixtures $( \pm)$-homocrepodine $\mathrm{A}[( \pm)-13]$, showed a moderate inhibitory effect $\left(\mathrm{IC}_{50}=5.0 \mu \mathrm{M}\right)$. Similar pharmacological activities were observed in ( \pm )-dendrocrepidamine A $[( \pm)-14]$ (Hu et al., 2020). Compared with the enantiomers of racemic indolizidine and their racemic mixtures, homocrepidine B (15) also displayed moderate anti-inflammatory activity with the $\mathrm{IC}_{50}$ value of $27.6 \mu \mathrm{M}$ ( $\mathrm{Hu}$ et al., 2016). Furthermore, the total alkaloids, mainly consisted of six indolizine-type compounds from the same Dendrobium species, showed protective effects against the LPS-induced acute lung injury in mice by the down-regulation of the TLR4-mediated MyD88/MAPK signaling pathway ( $\mathrm{Hu}$ et al., 2018). Taken together, the pharmacological investigations of Dendrobium alkaloids on anti-inflammatory shed light on scientific guidance for the source of this genus.

\section{Improved Regulation of Hepatic Lipid Homeostasis and Gluconeogenesis}

The liver is quite essential to the regulation of lipid and glucose homeostasis. On the other hand, the disruption of homeostasis will result in metabolic disorders of the liver, including fatty liver and diabetes, which are the most common chronic liver disease all over the world (Rinella, 2015). DNLA was found to impact the regulation of liver glucose and the expressions of lipid metabolism genes in mice livers by increasing the expressions of PGC1a, Glut2, Cpt1a, Acox, ATGL/Pnpla2, and FoxO1 genes, and decreasing the mRNA transcription from the Srebp1 gene (Xu et al., 2017). Moreover, excessive accumulation of hepatic lipids is responsible for liver metabolic dysfunction. Modulation of bile acids has been reported as an effective intervention strategy for maintaining hepatic lipid homeostasis (Chiang, 2013). DNLA exerted protective effects on hepatic lipid homeostasis by enhancing taurine-conjugated bile acids and decreasing the cholic acid/chenodeoxycholic acid ratio (Huang S. et al., 2019). To be specific, DNLA decreased four types of bile acids and increased five types of bile acids among 48 kinds of hepatic bile acids in the livers of high-fat diet (HFD)-fed mice (Huang S. et al., 2019). On the other hand, DNLA regulated hepatic gluconeogenesis by mediating the hepatic antioxidant components through hepatic metallothionein and the gene expression of the nuclear factor erythroid 2-related factor 2 antioxidant pathway, which plays critical roles in host defense against abnormal gluconeogenesis (Xu et al., 2017). The mechanisms were further elucidated that DNLA improved mitochondrial function and inhibited mitochondrial apoptotic cell death (Zhou et al., 2020). Overall, considering the beneficial effects of Dendrobium alkaloids on liver metabolism, Dendrobium alkaloids could be used as natural compounds in the development of new treatments for hyperlipidemia and hyperglycaemia.

\section{Anti-tumor Activity}

It was reported that Dendrobium alkaloids could inhibit tumor cell growth and mediate apoptosis. (He et al., 2017; Song et al., 2019; Wang et al., 2014). Specifically, the alkaloid extracts of Dendrobium candidum Wall. ex Lindl. were reported to significantly inhibit the growth of transplanted Lewis tumors, meanwhile, the mixed alkaloids could improve the spleen index and regulate the expressions of TNF- $\alpha$ and IL-2 (Wang et al., 2014). Moreover, the fat-soluble alkaloids extracted from Dendrobium nobile Lindl. were found to induce the apoptosis of human colorectal cancer HT-29 cells with an $\mathrm{IC}_{50}$ value of $0.72 \mathrm{mg} / \mathrm{ml}$ at $48 \mathrm{~h}$, where the cell cycle was arrested in G2 phase. Besides, the extraction decreased the mitochondrial membrane potential $(\Delta \Psi \mathrm{m})$ and induced ROS accumulation by increasing expression levels of apoptotic proteins, such as Caspase-9, Caspase-3, and intracellular cytochrome C (He et al., 2017), which may be related to the mitochondria-mediated apoptotic pathway. The combined treatment using sesquiterpene alkaloids, dendrobine (20) and cisplatin, was also effective for inhibiting the non-small cell lung cancer cells (NSCLC) in vitro and in vivo, where the cytotoxicity was induced by the simulation of $\mathrm{c}$-jun $\mathrm{NH}_{2}$-terminal kinase (JNK)/p38 stress signaling pathways, and the expression change of pro-apoptotic proteins Bax and Bim further led to the apoptosis (Figure 6, revised from song et al., 2019, created with BioRender.com). Besides, dendrobine (20) also mediated apoptotic cell death by the mitochondrial-mediated pathway (Song et al., 2019). On the whole, due to the distinct association with cell death signaling pathways, dendrobine (20) 

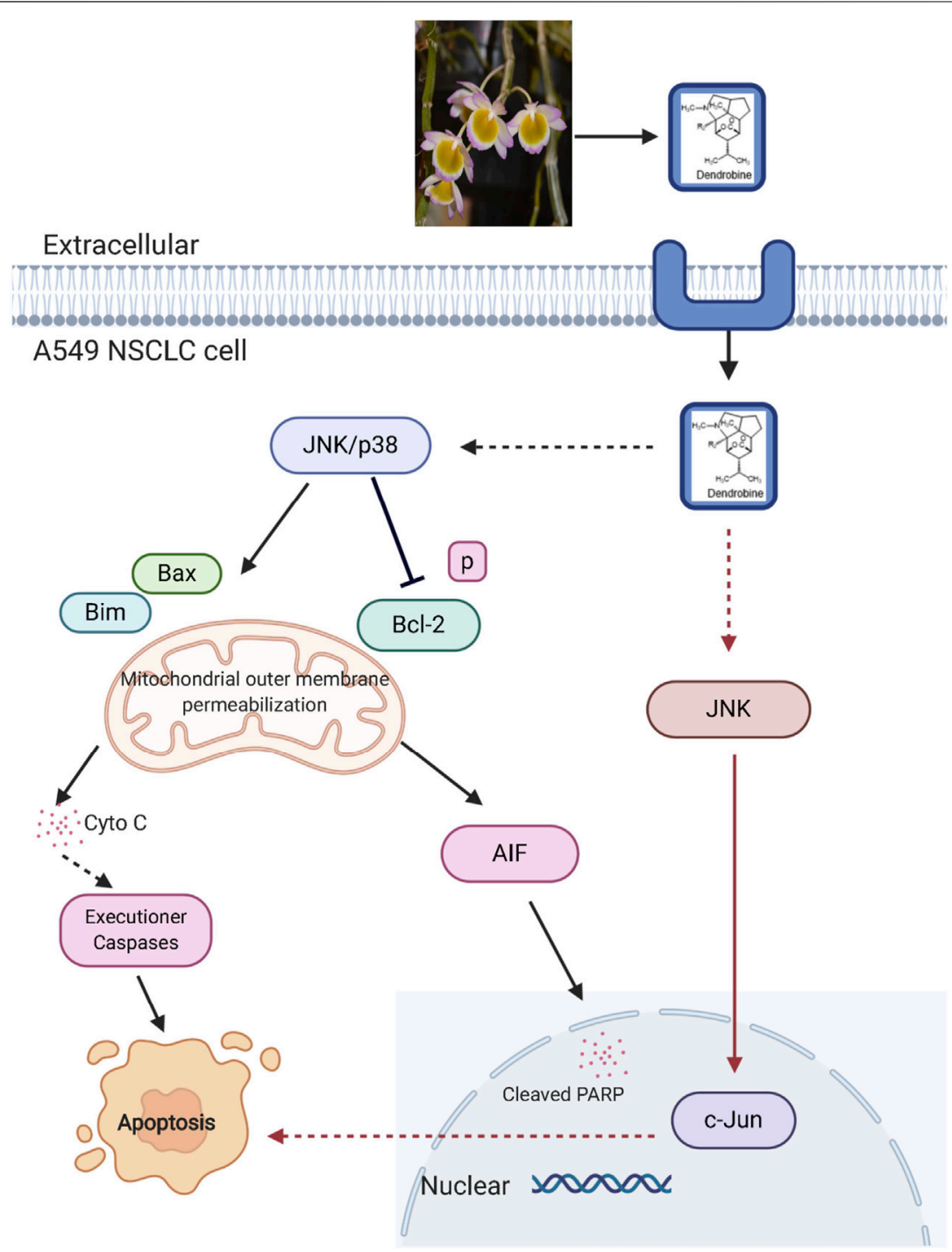

FIGURE 6 | Signaling pathway involved in dendrobine induced apoptosis in cancer cells. JNK, c-Jun N-terminal kinase; p38, p38 mitogenactivated protein kinase; Cyto C, cytochrome C; AlF, apoptosis inducing factor; Blc-2, B-cell lymphoma two; Bim, Bcl-2 interacting mediator of cell death; PARP, poly ADP-ribose polymerase.

can be regarded as a potential agent for the development of novel anti-NSCLS strategies especially when combined with cisplatin. (Song et al., 2019).

\section{Renal Protective and Anti-Diabetic Effects}

In China, the dried stems of some Dendrobium species including Dendrobium huoshanense Z. Z. Tang et S. J. Cheng, Dendrobium officinale Kimura et Migo, and Dendrobium nobile Lindl. have been used to nourish kidney and improve the symptoms of diabetes (Cakova et al., 2020). For instance, shihunidine (2) and shihunine (1) isolated from Dendrobium loddigesii Rolfe displayed inhibitory effects on $\mathrm{Na}^{+} / \mathrm{K}^{+}$-ATPase of the rat kidney (Li et al., 1991). Li et al. (2019) recently reported that DNLA showed vital hypoglycemic effects in diabetic rats. The shihunine (1) extracts from Dendrobium loddigesii Rolfe at the dose of $50 \mathrm{mg} / \mathrm{kg}$ decreased the triglycerides level by $43.7 \%$, compared with the non-treated $\mathrm{db} / \mathrm{db}$ mice, and inhibited the expression of cleaved cysteine aspartic acid-specific protease 3 . The result of western blot analysis also verified the agonistic effects of shihunine (1) extracts on the expressions of adenosine monophosphate-activated protein kinase phosphorylation and glucose transporter four in the liver or adipose tissues. Moreover, in clinical application, Dendrobium combined with other herbs, such as Astragalus spp. and Schisandra Michx., was applied for the therapy of diabetes (Cakova et al., 2020).

\section{Neuro-Protective Activity}

It was reported that Dendrobium alkaloids exerted beneficial effects on neuronal systems (Wang et al., 2010; Li et al., 2011), among which Dendrobium nobile Lindl. was most extensively studied on the treatment of central nervous system disorders. DNLA, containing dendrobine (20), dendrobine-N-oxide (22), 
nobilonine (45), dendroxine (24), 6-hydroxy-nobilonine (46), and 3-hydroxy-2-oxodendrobine (also referred as 13-hydroxy-14oxoHudendrobine) (26), was known as the active components of Dendrobium nobile Lindl. (Wang et al., 2010; Xu et al., 2017; Nie et al., 2018). Investigation on the mechanisms underlying the neuroprotective effects of DNLA revealed that DNLA prominently improved the neurobehavioral performance and prevented LPS-induced elevation in tumor necrosis factor receptor one via inhibition of phosphorylated p38 mitogenactivated protein kinases and the downstream nuclear factor kappa-B signal pathway (Li et al., 2011; Ng et al., 2012). Moreover, DNLA decreased the level of intracellular amyloid $\beta$ peptide $(\mathrm{A} \beta)$ by improving impaired autolysosomal proteolysis in amyloid precursor protein/presenilin one mice (Nie et al., 2018), and regulating $\alpha$ - and $\beta$-secretase in hippocampal neurons of Sprague-Dawley rats (Huang J. et al., 2019). The reduction of $\mathrm{A} \beta$ attenuated $\mathrm{A} \beta_{25-35}$-induced spatial learning and memory impairments by increasing the protein expression of neurotrophic factors, such as brain-derived neurotrophic factor, ciliary neurotrophic factor, and glial cell line-derived neurotrophic factor (Nie et al., 2016; Nie et al., 2018). Furthermore, DNLA lowered the LPS-induced hyperphosphorylation of tau protein and prevented neuronal apoptosis in rat brains (Yang et al., 2014). Given the neuro-protective effect of Dendrobium alkaloids, they could be promising therapeutic agents for the treatment of neurodegenerative disorders, such as Alzheimer's disease (Cakova et al., 2020).

\section{Anti-influenza A Virus Activity}

Dendrobine (20) displayed antiviral activity against influenza A viruses, including A/FM-1/1/47 (H1N1), A/Puerto Rico/8/34 $\mathrm{H} 274 \mathrm{Y}$ (H1N1), and A/Aichi/2/68 (H3N2) in the antiviral assay, plaque assay, time-of-addition assay, and pseudovirus neutralization assay, with $\mathrm{IC}_{50}$ values of $3.39 \pm 0.32,2.16 \pm$ 0.91 , and $5.32 \pm 1.68 \mu \mathrm{g} / \mathrm{ml}$, respectively. The low $\mathrm{IC}_{50}$ values of dendrobine (20) indicated that this compound could be applied as potential promising agents to treat influenza virus infection $(\mathrm{Li}$ R. et al., 2017). More importantly, the anti-virus test using dendrobine (20) provided valuable information for the full application of the TCM named "shí hú" (Li R. et al., 2017).

\section{CHEMICAL SYNTHESIS AND BIOSYNTHETIC PATHWAY OF DENDROBINE}

Dendrobine (20) is the first identified sesquiterpene alkaloid from Dendrobium nobile Lindl., which is recommended as the exclusive chemical marker for the quality control of this species by Chinese Pharmacopoeia (2015 and 2020 edition). The rule suggested that the mass fraction of dendrobine (20) should be greater than $0.4 \%$ in the medicinal Dendrobium nobile Lindl..

\section{Chemical Synthesis of Dendrobine}

Dendrobine (20) with a complicated tetracyclic ring system and seven contiguous stereocenters displayed remarkable bioactivities. Up to now, several cases are available on the total chemical synthesis of dendrobine (20). Connolly and Heathcock (1985) first synthesized dendrobine (20) in 1985. Several decades later, Kreis and Carreira (2012) achieved the total chemical synthesis based on 18 cascaded reactions with a key amine group, and the main synthesis pathway is summarized in Figure 7 (Kreis and Carreira, 2012). Other three dendrobinealkaloids (-)-dendrobine (20) (-)-mubironine B (27), and (-)-dendroxine (24) were also obtained by total synthesis (Guo et al., 2018). Despite the advances of these total synthesis methods, it remains challenging to overcome the compound yield after a series of reactions (Li Q. et al., 2017).

\section{Biosynthesis of Dendrobine}

Dendrobine (20) belongs to the class of terpenoid indole alkaloids (TIAs) (Wang et al., 2020). The biogenetic pathway of TIAs is conservative among alkaloid-producing plants (Li Q. et al., 2017). Based on the results of transcriptome and metabolomic analysis, the putative dendrobine (20) biosynthetic pathway was proposed, and a series of key metabolic genes were labeled in Figure 8 (Guo et al., 2013; Li Q. et al., 2017; Chen et al., 2019).

Three core stages were involved in the biogenetic pathway, including the formation of isopentenyl diphosphate (IPP), the construction of sesquiterpene skeleton, and the process of post-modification. Firstly, the mevalonate (MVA) and 2-Cmethyl-D-erythritol 4-phosphate (MEP) pathways were considered as the upstream of dendrobine (20) biosynthetic pathway, mainly for the synthesis of IPP (Chen et al., 2019). Three key enzyme-coding genes involved in the MVA pathway, acetyl-CoA C-acetyltransferase (AACT) gene, phosphomevalonate kinase (PMK) gene, and diphosphomevalonate decarboxylase (MVD) gene, were observed to be positively associated with dendrobine (20) accumulation in Dendrobium nobile Lindl. through large-scale transcriptome sequencing, and then validated through qRTPCR analysis (Li Q. et al., 2017). In contrast, hydroxymethylglutaryl-CoA synthase (HMGS) gene and 3hydroxy-3-methylglutaryl coenzyme A reductase (HMGR) gene were found to be less effective in dendrobine (20) biosynthesis in the same species (Li Q. et al., 2017), though HMGS and HMGR both played significant roles in alkaloid biosynthesis in Dendrobium officinale Kimura et Migo (Chen et al., 2019). The result shows that HMGS and HMGR may differently contribute to the production of dendrobine (20) in Dendrobium spp.. In the MEP pathway, rate-determining genes 1-deoxy-D-xylulose-5-phosphate synthase (DXS) and 1-deoxyD-xylulose-5-phosphate reductoisomerase (DXR) isolated from protocorms of Dendrobium officinale Kimura et Migo were largely up-regulated by the methyl jasmonate (MeJA) treatment, suggesting their significant roles in the sesquiterpene biosynthesis based on the analysis of KEGG enrichment and relative expression (Fan et al., 2016; Chen et al., 2019). The crucial impacts of DXS and DXR in Dendrobium officinale Kimura et Migo were later confirmed by the high correlations between total alkaloid contents and their transcripts (Chen et al., 2019), furthermore, DXS was a leaf-specific expression gene accounting for high alkaloids content in leaves (Shen et al., 2017). 


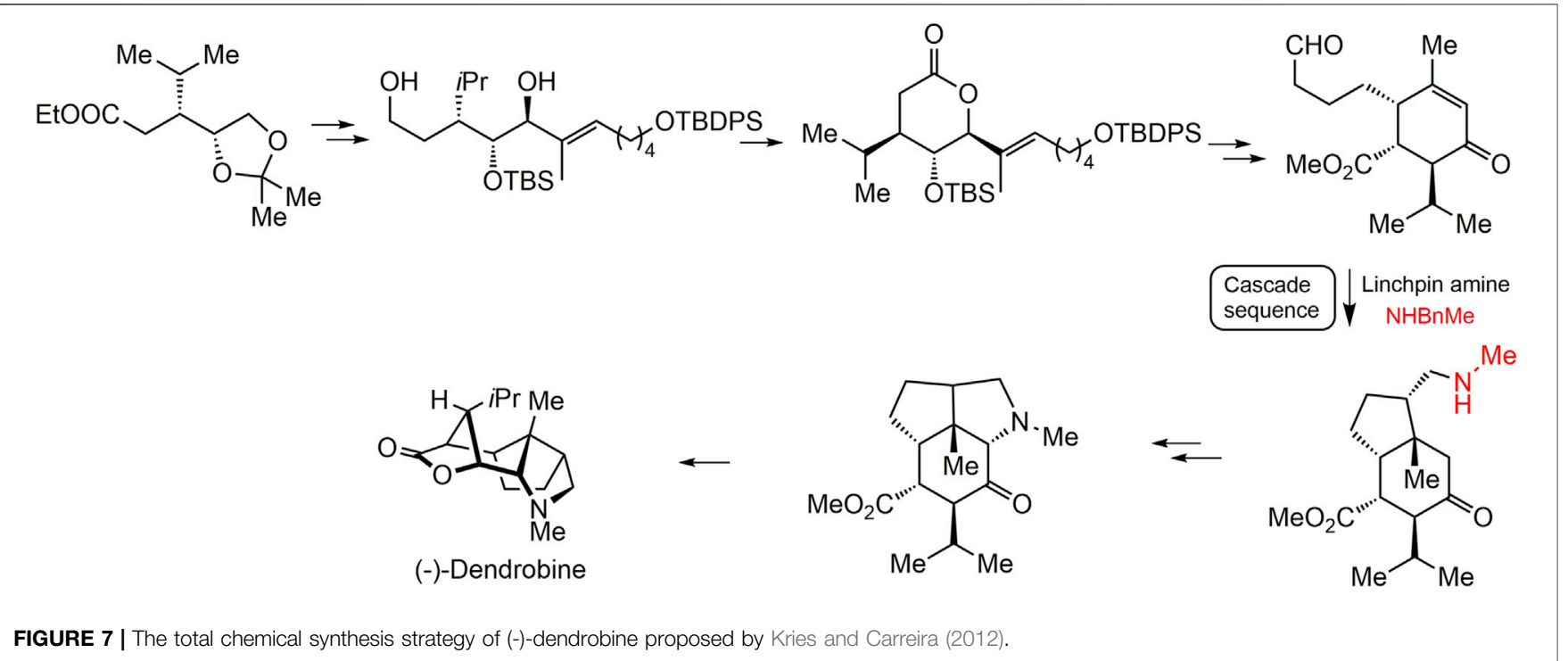

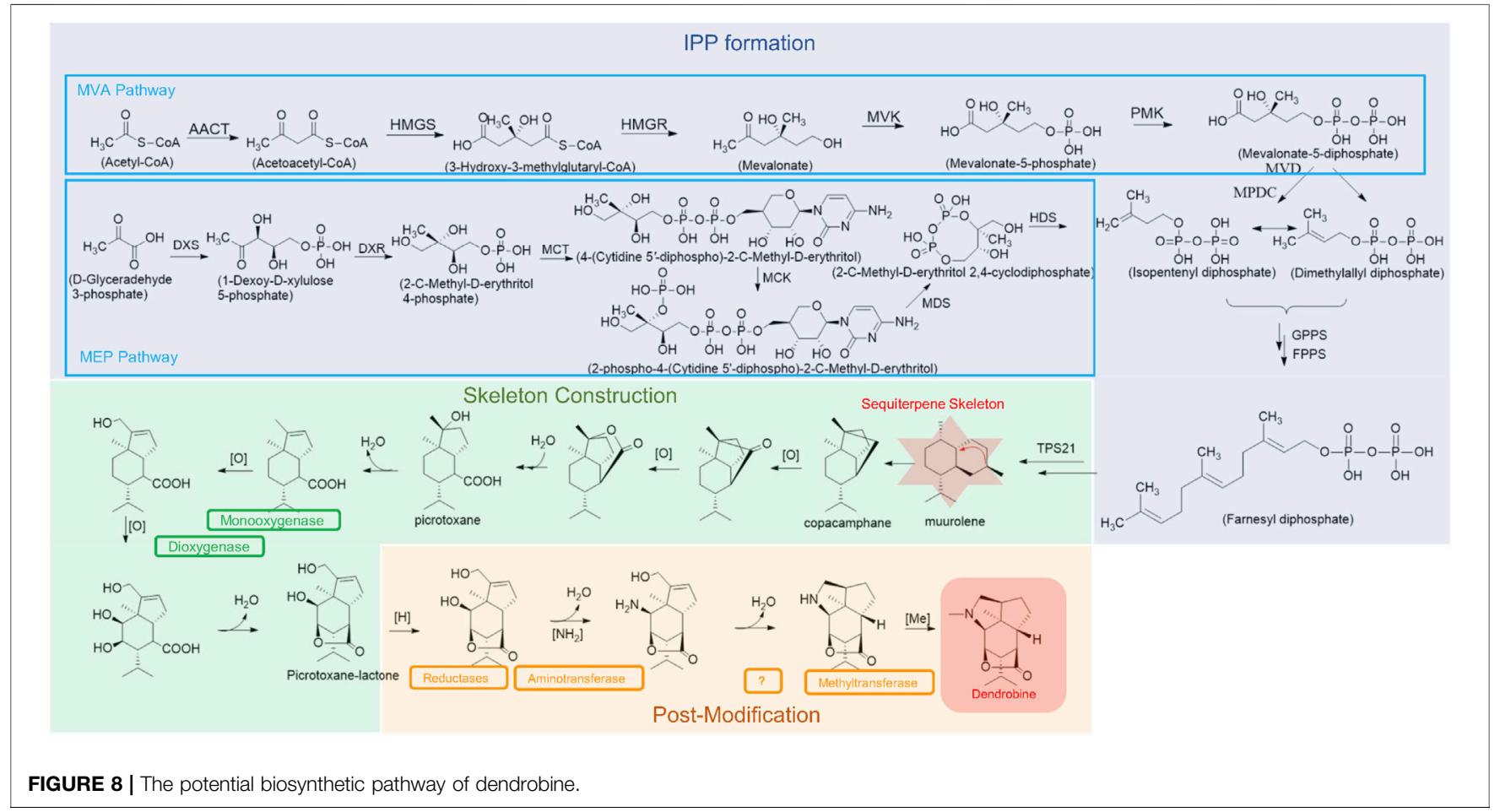

IPP is an important downstream product of MVA and MEP pathways, which is the precursor for the construction of synthetic terpenes. IPP formed the skeleton of muurolenetype sesquiterpene initially catalyzed by TPS2 1 enzyme (Li Q. et al., 2017), then this sesquiterpene was further oxidized by monooxygenases and/or dioxygenase to produce picrotoxanelactone. Cytochromes P450s (CYP450s) is a complex superfamily of monooxygenase, and they are vital for the formation of sesquiterpene alkaloids (dendrobine). At present, some CYP450s have been discovered in a few
Dendrobium species (Coon, 2005; Guo et al., 2013; Li Q. et al., 2017; Yuan et al., 2018; Chen et al., 2019). For instance, 59 full-length CYP450s candidate genes involved in the dendrobine (20) biosynthesis were identified and characterized in Dendrobium officinale Kimura et Migo through tissue-specific transcriptomic analysis, phylogenetic analysis, and further gene expression pattern induced by MeJA treatment (Chen et al., 2019). In Dendrobium huoshanense Z. Z. Tang et S. J. Cheng, 229 genes were identified as putative CYP450s, $7.8 \%$ of which were CYP71 family members 
associated with hydroxylation steps of alkaloid biosynthesis (Yuan et al., 2018). However, the family members and expression patterns of CYP450s remain unclear in most Dendrobium plants. It is worth mentioning that all other 25 dendrobine-type alkaloids $(20-42,51-52)$ identified from Dendrobium were believed to share similar biosynthesis pathways due to the mutual sesquiterpene backbone of these alkaloids (Guo et al., 2013; Chen et al., 2019).

Following the generation of sesquiterpene skeleton, dendrobine (20) was finally synthesized by the postmodification of picrotoxane-lactone with a series of enzymes, including reductases, aminotransferases, and methyltransferases (Guo et al., 2013; Yuan et al., 2018). In Dendrobium nobile Lindl., the expression level of methyltransferase-like protein 23 (METTL23) gene, histone-lysine N-methyltransferase ATX4 (ATX4) gene, and alanine aminotransferase 2 (AAT2) gene were enhanced after inoculation with MF23 (Mycena sp.), which was positively related with the content of dendrobine (20), implying their important roles in dendrobine (20) biosynthesis ( $\mathrm{Li}$ Q. et al., 2017). Transcription factors play vital roles in modulating the expression of dendrobine (20) biosynthesis genes, such as $\mathrm{C} 3 \mathrm{H}, \mathrm{bHLH}, \mathrm{bZIP}, \mathrm{MYB}$, and WRKY in Dendrobium officinale Kimura et Migo (Yuan et al., 2018).

Although the common biosynthesis pathway for most TIAs through the construction of strictosidine backbone exists in many plants (Wang et al., 2018), no enzyme involved in strictosidine formation has been verified in dendrobine (20) biosynthesis. However, due to the complex dendrobine (20) metabolism, accurate identification of genetic networks from a large number of candidate genes is needed in the future.

The metabolism of dendrobine (20) was affected by abiotic and biotic stresses. For example, light intensity was reported to influence the content of dendrobine (20) (Li J. L. et al., 2017). MeJA, a signaling molecule in the biosynthesis of alkaloids, could induce the accumulation of Dendrobium alkaloids by an active precursor supply (Chen et al., 2019). Besides, symbiosis with mycorrhizal fungus could stimulate the biosynthesis of dendrobine $(20)$ by regulating the expressions of genes

\section{REFERENCES}

Begum, S. A., Sahai, M., Ray, A. B., Gössinger, E., Luzhetska, M., Härle, J., et al. (2010). Progress in the Chemistry of Organic Natural Products: Picrotoxanes. Vienna, Austria: Springer.

Cakova, V., Bonte, F., and Lobstein, A. (2020). Dendrobium: Sources of Active Ingredients to Treat Age Related Pathologies. Aging Dis. 2, 827-849. 10.14336/ AD.2017.0214

Chase, M. W., Cameron, K. M., Freudenstein, J. V., Pridgeon, A. M., Salazar, G., Van den Berg, C., et al. (2015). An Updated Classification of Orchidaceae. Bot. J. Linn. Soc. 177, 151-174. doi:10.1111/boj.12234

Chen, H., Li, X., Xu, Y., Lo, K., Zheng, H., Hu, H., et al. (2018). Study on the Polar Extracts of Dendrobium Nobile, D. Officinale, D. Loddigesii, and Flickingeria Fimbriata: Metabolite Identification, Content Evaluation, and Bioactivity Assay. Molecules 23, 1185. doi:10.3390/molecules23051185

Chen, K. K., and Chen, A. L. (1935). The Alkaloid of Chin-Shih-Hu. J. Biol. Chem. 111, 653-658. doi:10.1016/s0021-9258(18)75010-2 involved in the MVA pathway (Li Q. et al., 2017). Other relevant factors need to be further elucidated.

\section{CONCLUSION}

In this paper, we summarized the structural types, pharmacological activities, and mechanisms of Dendrobium alkaloids, as well as the suggested biogenetic pathway of dendrobine (20), which is an important type of sesquiterpene alkaloids. Despite the advances of the investigation on alkaloids, more emphasis should be laid on the discovery of more novel skeletons in Dendrobium genus based on abundant alkaloid metabolites, and the improvement of isolation methods. Moreover, many current studies on Dendrobium were only focused on their crude extracts, or the activity of mixtures, which necessitates the need for figuring out the typical pharmacological activity of pure Dendrobium alkaloids. Additionally, further investigation on novel pharmacological activities of these alkaloids should be implemented. Meanwhile, in-depth researches on the biological mechanisms of these activities are also desired. Finally, although the biosynthetic pathway of dendrobine (20) has been proposed, further confirmation is anticipated.

\section{AUTHOR CONTRIBUTIONS}

DZ and SC contributed to the conception of the review. YZ and EK helped collect and perform the chemical analysis of compounds. FY helped to analyze the pharmacological activities of alkaloids. ZM and YS contributed to the mechanisms and biosynthetic pathways of alkaloids and wrote the manuscript.

\section{FUNDING}

This work was supported financially by the National Natural Science Foundation of China (No. 31960082; No. 81560622).

Chen, Y., Wang, Y., Lyu, P., Chen, L., Shen, C., and Sun, C. (2019). Comparative Transcriptomic Analysis Reveal the Regulation Mechanism Underlying MeJAInduced Accumulation of Alkaloids in Dendrobium Officinale. J. Plant Res. 132, 419-429. doi:10.1007/s10265-019-01099-6

Chiang, J. Y. L. (2013). Bile Acid Metabolism and Signaling. Compr. Physiol. 3, 1191-1212. doi:10.1002/cphy.c120023

Chinese Pharmacopoeia Commission (2020). Pharmacopoeia of the People's Republic of China. Beijing, China: China Medical Science Press, 263.

Connolly, P. J., and Heathcock, C. H. (1985). An Approach to the Total Synthesis of Dendrobine. J. Org. Chem. 50, 4135-4144. doi:10.1021/jo00221a033

Coon, M. J. (2005). Cytochrome P450: Nature's Most Versatile Biological Catalyst. Annu. Rev. Pharmacol. Toxicol. 45, 1-25. doi:10.1146/annurev.pharmtox.45.120403.100030

Ekevag, U., Elander, M., Gawell, L., Leander, K., Lüning, B., and Swahn, C.-G. (1973). Studies on Orchidaceae Alkaloids. XXXIII. Two New Alkaloids, N-Cisand N-Trans-Cinnamoylnorcuskhygrine from Dendrobium Chrysanthum Wall. Acta Chem. Scand. 27, 1982-1986. doi:10.3891/acta.chem.scand.27-1982 Elander, M., Leander, K., Klæboe, P., Cyvin, S. J., Lagerlund, I., and Ehrenberg, L. (1971). Studies on Orchidaceae Alkaloids. XXI. 6-hydroxynobiline, a New 
Alkaloid from Dendrobium Hildebrandii Rolfe. Acta Chem. Scand. 25, 717-720. doi:10.3891/acta.chem.scand.25-0717

Elander, M., Leander, K., Lüning, B., Holme, T., Lindberg, A. A., and Craig, J. C. (1969). Studies on Orchidaceae Alkaloids. XIV. A Phthalide Alkaloid from Dendrobium Pierardii Roxb. Acta Chem. Scand. 23, 2177-2178. doi:10.3891/ acta.chem.scand.23-2177

Elander, M., Leander, K., Rosenblom, J., Ruusa, E., Lüning, B., and Swahn, C. G. (1973). Studies on Orchidaceae Alkaloids. XXXII. Crepidine, Crepidamine and Dendrocrepine, Three Alkaloids from Dendrobium Crepidatum Lindl. Acta Chem. Scand. 27, 1907-1913. doi:10.3891/acta.chem.scand.27-1907

Fan, H., Wu, Q., Wang, X., Wu, L., Cai, Y., and Lin, Y. (2016). Molecular Cloning and Expression of 1-Deoxy-D-Xylulose-5-Phosphate Synthase and 1-Deoxy-DXylulose-5-Phosphate Reductoisomerase in Dendrobium Officinale. Plant Cell Tiss. Organ. Cult. 125, 381-385. doi:10.1007/s11240-016-0945-1

Flora of China (2020). Flora of China. Available at: www.efloras.org (Accessed March 27, 2021).

Glomqvist, L., Brandänge, S., Gawell, L., Leander, K., and Lüning, B. (1973). Studies on Orchidaceae Alkaloids. XXXVII. Dendrowardine, a Quaternary Alkaloid from Dendrobium Wardianum Wr. Acta Chem. Scand. 27, 1439-1441. doi:10. 3891/acta.chem.scand.27-1439

Granelli, I., Leander, K., Lüning, B., Liaaen-Jensen, S., Lamvik, A., Sunde, E., et al. (1970). Studies on Orchidaceae Alkaloids. XVI. A New Alkaloid, 2Hydroxydendrobine, from Dendrobium findlayanum Par. et Rchb. f. Acta Chem. Scand. 24, 1209-1212. doi:10.3891/acta.chem.scand.24-1209

Guha, M., and Mackman, N. (2001). LPS Induction of Gene Expression in Human Monocytes. Cell Signal. 13, 85-94. doi:10.1016/s0898-6568(00)00149-2

Guo, X., Li, Y., Li, C., Luo, H., Wang, L., Qian, J., et al. (2013). Analysis of the Dendrobium Officinale Transcriptome Reveals Putative Alkaloid Biosynthetic Genes and Genetic Markers. Gene 527, 131-138. doi:10.1016/j.gene.2013. 05.073

Guo, L., Frey, W., and Plietker, B. (2018). Catalytic Enantioselective Total Synthesis of the Picrotoxane Alkaloids (-)-Dendrobine, (-)-Mubironine $\mathrm{B}$, and (-)-Dendroxine. Org. Lett. 20, 4328-4331. doi:10.1021/acs.orglett.8b01782

He, L., Luo, J., Wang, Y. Y., Shi, Y. J., and Ren, J. W. (2017). Fat-soluble Alkaloids Extracted from Dendrobium Nobile Lindl Induced Apoptosis of Human Colorectal Cancer HT-29 Cells. Sci. Tech. Food Ind. 38, 170-174.

He, L., Su, Q., Bai, L., Li, M., Liu, J., Liu, X., et al. (2020). Recent Research Progress on Natural Small Molecule Bibenzyls and its Derivatives in Dendrobium Species. Eur. J. Med. Chem. 204, 112530. doi:10.1016/j.ejmech.2020.112530

Hedman, K., Leander, K., Liaaen-Jensen, S., Tricker, M. J., and Svensson, S. (1972). Studies on Orchidaceae Alkaloids. XXVII. Quaternary Salts of the Dendrobine Type from Dendrobium Nobile Lindl. Acta Chem. Scand. 26, 3177-3180. doi:10. 3891/acta.chem.scand.26-3177

Hemscheidt, T., and Spenser, I. D. (1993). Biosynthesis of Anosmine: Incorporation of the Intact Six-Carbon Chain of Lysine and of Pipecolic Acid. J. Nat. Prod. 56, 1281-1287. doi:10.1021/np50098a012

Hu, Y., Zhang, C., Zhao, X., Wang, Y., Feng, D., Zhang, M., et al. (2016). $( \pm)$-Homocrepidine A, a Pair of Anti-inflammatory Enantiomeric Octahydroindolizine Alkaloid Dimers from Dendrobium Crepidatum. J. Nat. Prod. 79, 252-256. doi:10.1021/acs.jnatprod.5b00801

Hu, Y., Ren, J., Wang, L., Zhao, X., Zhang, M., Shimizu, K., et al. (2018). Protective Effects of Total Alkaloids from Dendrobium Crepidatum against LPS-Induced Acute Lung Injury in Mice and its Chemical Components. Phytochemistry 149, 12-23. doi:10.1016/j.phytochem.2018.02.006

Hu, Y., Yang, H., Ding, X., Liu, J., Wang, X., Hu, L., et al. (2020). Antiinflammatory Octahydroindolizine Alkaloid Enantiomers from Dendrobium Crepidatum. Bioorg. Chem. 100, 103809. doi:10.1016/j.bioorg.2020.103809

Huang, J., Huang, N., Zhang, M., Nie, J., Xu, Y., Wu, Q., et al. (2019). Dendrobium Alkaloids Decrease $A \beta$ by Regulating $\alpha$ - and $\beta$-secretases in Hippocampal Neurons of SD Rats. PeerJ 7, e7627. doi:10.7717/peerj.7627

Huang, S., Wu, Q., Liu, H., Ling, H., He, Y., Wang, C., et al. (2019). Alkaloids of Dendrobium Nobile Lindl. Altered Hepatic Lipid Homeostasis Regulation of Bile Acids. J. Ethnopharmacol. 241, 111976. doi:10.1016/j.jep.2019.111976

Inubushi, Y., Ishii, H., Yasui, B., Konita, T., and Harayama, T. (1964). Isolation and Characterization of Alkaloids of the Chinese Drug "Chin-Shih-Hu". Chem. Pharm. Bull. 12, 1175-1180. doi:10.1248/cpb.12.1175

Inubushi, Y., and Nakano, J. (1965). Structure of Dendrine. Tetrahedron Lett. 6, 2723-2728. doi:10.1016/s0040-4039(01)99532-2
Kreis, L. M., and Carreira, E. M. (2012). Total Synthesis of (-)-Dendrobine. Angew. Chem. Int. Ed. 51, 3436-3439. doi:10.1002/anie.201108564

Lam, Y., Ng, T. B., Yao, R. M., Shi, J., Xu, K., Sze, S. C., et al. (2015). Evaluation of Chemical Constituents and Important Mechanism of Pharmacological Biology in Dendrobium Plants. Evid. Based Complement. Alternat Med. 2015, 841752. doi:10.1155/2015/841752

Li, M. F., Hirata, Y., Xu, G. J., Niwa, M., and Wu, H. M. (1991). Studies on the Chemical Constituents of Dendrobium Loddigesii Rolfe. Yao Xue Xue Bao 26, 307-310.

Li, Y., Li, F., Gong, Q., Wu, Q., and Shi, J. (2011). Inhibitory effects of Dendrobium alkaloids on memory impairment induced by lipopolysaccharide in rats. Planta Med. 77, 117-121. doi:10.1055/s-0030-1250235

Li, J. L., Zhao, Z., Liu, H. C., Luo, C. L., and Wang, H. L. (2017). Influence of Light Intensity and Water Content of Medium on Total Dendrobine of Dendrobium Nobile Lindl. Asian Pac. J. Trop. Med. 10, 1095-1100. doi:10.1016/j.apjtm.2017. 10.015

Li, Q., Ding, G., Li, B., and Guo, S. X. (2017). Transcriptome Analysis of Genes Involved in Dendrobine Biosynthesis in Dendrobium Nobile Lindl. Infected with Mycorrhizal Fungus MF23 (Mycena sp.). Sci. Rep. 7, 7-16. doi:10.1038/ s41598-017-00445-9

Li, R., Liu, T., Liu, M., Chen, F., Liu, S., and Yang, J. (2017). Anti-influenza A Virus Activity of Dendrobine and its Mechanism of Action. J. Agric. Food Chem. 65, 3665-3674. doi:10.1021/acs.jafc.7b00276

Li, X. W., Huang, M., Lo, K., Chen, W. L., He, Y. Y., Xu, Y., et al. (2019). Antidiabetic Effect of a Shihunine-Rich Extract of Dendrobium Loddigesii on 3T3L1 Cells and Db/db Mice by Up-Regulating AMPK-GLUT4-Ppara. Molecules 24(14):2673. doi:10.3390/molecules24142673

Liang, X. M., Jin, Y., Wang, Y. P., Jin, G. W., Fu, Q., and Xiao, Y. S. (2009). Qualitative and Quantitative Analysis in Quality Control of Traditional Chinese Medicines. J. Chromatogr. A 1216, 2033-2044. doi:10.1016/j.chroma.2008. 07.026

Lin, X., Shi, H., Cui, Y., Wang, X., Zhang, J., Yu, W., et al. (2018). Dendrobium Mixture Regulates Hepatic Gluconeogenesis in Diabetic Rats via the Phosphoinositide-3-Kinase/protein Kinase B Signaling Pathway. Exp. Ther. Med. 16, 204-212. doi:10.3892/etm.2018.6194

Liu, G. Y., Tan, L., Cheng, L., Ding, L. S., Zhou, Y., Deng, Y., et al. (2020). Dendrobine-type Alkaloids and Bibenzyl Derivatives from Dendrobium Findlayanum. Fitoterapia 142, 104497. doi:10.1016/j.fitote.2020.104497

Liu, Q. F., and Zhao, W. M. (2003). A New Dendrobine-type Alkaloid from Dendrobium Nobile. Chin. Chem. Lett. 14, 278-279.

Liu, W. H., Hua, Y. F., and Zhan, Z. J. (2007). Moniline, a New Alkaloid from Dendrobium Moniliforme. J. Chem. Res. 2007, 317-318. doi:10.3184/ $030823407 X 218048$

Lüning, B., Leander, K., Gröndahl, N. J., Guthrie, C., and Hinton, M. (1965). Studies on Orchidaceae Alkaloids. III. The Alkaloids in Dendrobium Primulinum Lindl. And Dendrobium Chrysanthum Wall. Acta Chem. Scand. 19, 1607-1611. doi:10.3891/acta.chem.scand.19-1607

Meng, C. W., He, Y. L., Peng, C., Ding, X. J., Guo, L., and Xiong, L. (2017). Picrotoxane Sesquiterpenoids from the Stems of Dendrobium Nobile and Their Absolute Configurations and Angiogenesis Effect. Fitoterapia 121, 206-211. doi:10.1016/j.fitote.2017.07.017

Morita, H., Fujiwara, M., Yoshida, N., and Kobayashi, J. I. (2000). New Picrotoxinin-type and Dendrobine-type Sesquiterpenoids from Dendrobium Snowflake 'Red Star'. Tetrahedron 56, 5801-5805. doi:10.1016/s0040-4020(00) 00530-5

Ng, T. B., Liu, J., Wong, J. H., Ye, X., Wing Sze, S. C., Tong, Y., et al. (2012). Review of Research on Dendrobium, a Prized Folk Medicine. Appl. Microbiol. Biotechnol. 93, 1795-1803. doi:10.1007/s00253-011-3829-7

Nie, J., Jiang, L., Lu, Y., and Shi, J. (2018). Dendrobium Nobile Lindl. Alkaloids Decreases the Level of Intracellular $\beta$-amyloid by Improving Impaired Autolysosomal Proteolysis in APP/PS1 Mice. Front. Pharmacol. 9, 1479. doi:10.3389/fphar.2018.01479

Nie, J., Tian, Y., Zhang, Y., Lu, Y. L., Li, L. S., and Shi, J. S. (2016). Dendrobium Alkaloids Prevent A $\beta_{25-35}$-inducted Neuronal and Synaptic Loss via Promoting Neurotrophic Factor Expression in Mice. PeerJ 4, e2739. doi: $10.7717 /$ peerj. 2739

Okamoto, T., Natsume, M., Onaka, T., Uchimaru, F., and Shimizu, M. (1972). Further Studies on the Alkaloidal Constituents of Dendrobium Nobile 
(Orchidaceae)-Structure Determination of 4-Hydroxy-Dendroxine and Nobilomethylene. Chem. Pharm. Bull. 20, 418-421. doi:10.1248/cpb.20.418

Okamoto, T., Natsume, M., Onaka, T., Uchimaru, F., and Shimizu, M. (1966a). The Structure of Dendramine (6-Oxydendrobine) and 6-Oxydendroxine the Fourth and Fifth Alkaloid from Dendrobium Nobile. Chem. Pharm. Bull. 14, 676-680. doi: $10.1248 / \mathrm{cpb} .14 .676$

Okamoto, T., Natsume, M., Onaka, T., Uchimaru, F., and Shimizu, M. (1966b). The Structure of Dendroxine the Third Alkaloid from Dendrobium Nobile. Chem. Pharm. Bull. 14, 672-675. doi:10.1248/cpb.14.672

Rinella, M. E. (2015). Nonalcoholic Fatty Liver Disease: a Systematic Review. Jama 313, 2263-2273. doi:10.1001/jama.2015.5370

Shen, C., Guo, H., Chen, H., Shi, Y., Meng, Y., Lu, J., et al. (2017). Identification and Analysis of Genes Associated with the Synthesis of Bioactive Constituents in Dendrobium Officinale Using RNA-Seq. Sci. Rep. 7, 187. doi:10.1038/s41598017-00292-8

Shhosuke, Y., and Yoshimasa, H. (1964). Structures of Nobiline and Dendrobine. Tetrahedron Lett. 5, 79-87. doi:10.1016/S0040-4039(00)90333-2

Song, C., Jiao, C., Jin, Q., Chen, C., Cai, Y., and Lin, Y. (2020). Metabolomics Analysis of Nitrogen-Containing Metabolites between Two Dendrobium Plants. Physiol. Mol. Biol. Plants. 26, 1425-1435. doi:10.1007/s12298-020-00822-1

Song, T. H., Chen, X. X., Lee, C. K. F., Sze, S. C. W., Feng, Y. B., Yang, Z. J., et al. (2019). Dendrobine Targeting JNK Stress Signaling to Sensitize Chemotoxicity of Cisplatin against Non-small Cell Lung Cancer Cells In Vitro and In Vivo. Phytomedicine 53, 18-27. doi:10.1016/j.phymed.2018.06.018

Wang, H., Zhao, T., and Che, C. T. (1985). Dendrobine and 3-Hydroxy-2Oxodendrobine from Dendrobium Nobile. J. Nat. Prod. 48, 796-801. doi:10. 1021/np50041a014

Wang, J., Ge, Y., Zhou, C., Tong, Y., and Ren, Z. (2014). Study on the Mechanism of Extracts from Fresh Dendrobium Candidum against Lewis Lung Cancer. Chin. J. Mod. Appl. Pharm. 31, 953-957.

Wang, P., Chen, X., Wang, H., Huang, S., Cai, C., Yuan, J., et al. (2019). Four New Picrotoxane-type Sesquiterpenes from Dendrobium Nobile Lindl. Front. Chem. 7, 812. doi: $10.3389 /$ fchem. 2019.00812

Wang, Q., Gong, Q., Wu, Q., and Shi, J. (2010). Neuroprotective Effects of Dendrobium Alkaloids on Rat Cortical Neurons Injured by Oxygen-Glucose Deprivation and Reperfusion. Phytomedicine 17, 108-115. doi:10.1016/j. phymed.2009.05.010

Wang, Q., Liang, J., Brennan, C., Ma, L., Li, Y., Lin, X., et al. (2019). Antiinflammatory Effect of Alkaloids Extracted from Dendrobium Aphyllum on Macrophage RAW 264.7 Cells through NO Production and Reduced IL-1, IL-6, TNF- $\alpha$ and PGE2 Expression. Int. J. Food Sci. Technol. 55, 1255-1264. doi:10. $1111 /$ ijfs. 14404

Wang, Z., Zhao, M., Cui, H., Li, J., and Wang, M. (2020). Transcriptomic Landscape of Medicinal Dendrobium Reveals Genes Associated with the Biosynthesis of Bioactive Components. Front. Plant Sci. 11, 391. doi:10. 3389/fpls.2020.00391

Xu, J., Han, Q. B., Li, S. L., Chen, X. J., Wang, X. N., Zhao, Z. Z., et al. (2013). Chemistry, Bioactivity and Quality Control of Dendrobium, a Commonly Used Tonic Herb in Traditional Chinese Medicine. Phytochem. Rev. 12, 341-367. doi:10.1007/s11101-013-9310-8

Xu, X., Li, Z., Yang, R., and Zhou, H., (2020). Crepidatumines A and B, Two New Indolizidine Alkaloids from Dendrobium Crepidatum Lindl. ex Paxt. Sci. Rep. 24, 3071. doi:10.3390/molecules24173071
Xu, X., Li, Z., Yang, R., Zhou, H., and Li, B. (2019). Crepidatumines C and D, Two New Indolizidine Alkaloids from Dendrobium Crepidatum Lindl. ex Paxt. Molecules 24, 3071. doi:10.3390/molecules24173071

Xu, Y. Y., Xu, Y. S., Wang, Y., Wu, Q., Lu, Y. F., Liu, J., et al. (2017). Dendrobium Nobile Lindl. Alkaloids Regulate Metabolism Gene Expression in Livers of Mice. J. Pharm. Pharmacol. 69, 1409-1417. doi:10.1111/jphp.12778

Yang, D., Cheng, Z. Q., Hou, B., Yang, L., Zi, C. T., Dong, F. W., et al. (2020). Two Unusual Dendrobine-type Alkaloids from Dendrobium Findlayanum. Fitoterapia 144, 104607. doi:10.1016/j.fitote.2020.104607

Yang, D., Cheng, Z. Q., Yang, L., Hou, B., Yang, J., Li, X. N., et al. (2018). Secodendrobine-type Alkaloids and Bioactive Phenolics from Dendrobium Findlayanum. J. Nat. Prod. 81, 227-235. doi:10.1021/acs.jnatprod.7b00150

Yang, L., Wang, Z., and Xu, L. (2006). Simultaneous Determination of Phenols (Bibenzyl, Phenanthrene, and Fluorenone) in Dendrobium Species by HighPerformance Liquid Chromatography with Diode Array Detection. J. Chromatogr. A 1104, 230-237. doi:10.1016/j.chroma.2005.12.012

Yang, L., Zhang, C., Yang, H., Zhang, M., Wang, Z., and Xu, L. (2005). Two New Alkaloids from Dendrobium Chrysanthum. Heterocycles 65, 633-636. 10.3987/ COM-04-10251.

Yang, S., Gong, Q., Wu, Q., Li, F., Lu, Y., and Shi, J. (2014). Alkaloids Enriched Extract from Dendrobium Nobile Lindl. Attenuates Tau Protein Hyperphosphorylation and Apoptosis Induced by Lipopolysaccharide in Rat Brain. Phytomedicine 21, 712-716. doi:10.1016/j.phymed.2013.10.026

Yuan, Y., Yu, M., Jia, Z., Song, X., Liang, Y., and Zhang, J. (2018). Analysis of Dendrobium Huoshanense Transcriptome Unveils Putative Genes Associated with Active Ingredients Synthesis. BMC Genomics 19, 978. doi:10.1186/s12864018-5305-6

Zhang, A. L., Yu, M., Xu, H. H., and Si, J. P. (2013). Constituents of Dendrobium Devonianum and Their Antioxidant Activity. Zhongguo Zhong Yao Za Zhi 38, 844-847.

Zhang, C., Liu, S. J., Yang, L., Yuan, M. Y., Li, J. Y., Hou, B., et al. (2017). Sesquiterpene Amino Ether and Cytotoxic Phenols from Dendrobium Wardianum Warner. Fitoterapia 122, 76-79. doi:10.1016/j.fitote.2017. 08.015

Zhou, J., Zhang, Y., Li, S., Zhou, Q., Lu, F., Shi, J., et al. (2020). Dendrobium Nobile Lindl. Alkaloids-Mediated Protection against $\mathrm{CCl}_{4}$-Induced Liver Mitochondrial Oxidative Damage Is Dependent on the Activation of Nrf2 Signaling Pathway. Biomed. Pharmcother. 129, 100351. doi:10.1016/j.biopha. 2020.110351

Zhu, G., J. Z., Wood, J., and Wood, H. (2009). Flora of China. Beijing, China: Science Press, 367-397.

Conflict of Interest: The authors declare that the research was conducted in the absence of any commercial or financial relationships that could be construed as a potential conflict of interest.

Copyright $\odot 2021$ Mou, Zhao, Ye, Shi, Kennelly, Chen and Zhao. This is an openaccess article distributed under the terms of the Creative Commons Attribution License (CC BY). The use, distribution or reproduction in other forums is permitted, provided the original author(s) and the copyright owner(s) are credited and that the original publication in this journal is cited, in accordance with accepted academic practice. No use, distribution or reproduction is permitted which does not comply with these terms. 